\title{
UM ESTUDO SOCIOTERMINOLÓGICO DO LÉXICO DO CORPO DE BOMBEIROS MILITAR DO MARANHÃO
}

\author{
José Claudio Bezerra Pereira*
}

RESUMO: Este artigo trata do léxico do Corpo de Bombeiros Militar do Maranhão (CBMMA), para registro e produção de um glossário. Justifica-se pela emancipação, em 1993, que permitiu originar um léxico especializado. Fundamenta-se na Terminologia e Socioterminologia, nos estudos de Barros (2004), Faulstich (1995), Krieger e Finatto (2004). Metodologicamente, fizemos uso de um questionário: os informantes foram distribuídos em três faixas de idade; como resultados, identificamos termos como Bob esponja, que se refere à comida do tipo torta. O presente trabalho é relevante para o estudo do léxico no país.

PALAVRAS-CHAVE: Corpo de bombeiros; Glossário; Socioterminologia; Terminologia.

\section{Introdução}

O marco do nosso trabalho é a emancipação administrativa e operacional do Corpo de Bombeiros Militar do Maranhão, doravante CBMMA, ocorrida em 1992 - ano em que essa corporação deixou de pertencer à Polícia Militar do Maranhão (PMMA) e passou a funcionar como um órgão independente dentro da Secretaria de Segurança Pública do Estado do Maranhão - uma vez que a hipótese principal que desencadeou o nosso estudo é a existência da produção de um léxico especializado dentro do CBMMA, sobretudo a partir de sua autonomia da PMMA e, consequentemente, do desmembramento e especificações de suas atividades.

Vale destacar que, anteriormente à emancipação, existiam, no Maranhão, somente três unidades dentro dessa instituição, que eram: o $1^{\circ}$ Grupamento de Bombeiros e a Seção de Combate a Incêndio em Aeronaves, ambas na capital do estado, São Luís, e o Grupamento de Bombeiros, em Imperatriz. Atualmente, o CBMMA encontra-se em dezoito municípios do Estado, mas somente na capital essa instituição executa suas atividades em segmentos

\footnotetext{
* Mestre em Letras pela Universidade Federal do Maranhão (Ufma).
} 
especializados ${ }^{1}$, além do combate ao incêndio, tais como: busca, salvamento terrestre, emergência médica (atendimento pré-hospitalar), resgate veicular, salvamento aquático e ambiental, incêndio em aeródromo, resgate de cadáveres.

Nossa atenção se volta, principalmente, para as unidades lexicais específicas de cada quartel especializado, concebidas por intermédio das atividades operacionais que cada quartel desempenha. Intuímos que nesse léxico especializado há diferenças de uso entre homens e mulheres de distintas faixas etárias.

As questões de investigação que demarcam a hipótese acima explicitada para confirmar ou refutar são: a) quais são as unidades lexicais que, de fato, particularizam as relações laborais dos profissionais do CBMMA? b) quais unidades lexicais são mais frequentes e/ou específicas em cada um dos quartéis especializados? c) os membros mais novos usam um léxico especializado diferente do usado pelos mais velhos? d) há diferenças consubstanciais entre o léxico especializado usado por homens e mulheres do CBMMA?

Logo, como objetivo principal desta pesquisa, temos a produção de um glossário do léxico especializado do Corpo de Bombeiros Militar do Maranhão, e como objetivos específicos estabelecemos: a) levantar as amostras do léxico especializado do CBMMA com base em narrativas orais livres de profissionais da reserva ou reformados ${ }^{2}$; b) elaborar um questionário, organizado em campos semânticos, a partir dos dados coletados nas narrativas; c) definir o perfil dos informantes; d) realizar entrevistas com base no questionário elaborado; e) transcrever as entrevistas realizadas; f) levantar e selecionar os termos para compor o glossário especializado do CBMMA; g) analisar os dados com base no perfil dos informantes.

Este estudo se fundamenta, sobretudo, nos estudos da Terminologia e da Socioterminologia, desenvolvidos por Auger (1993), Boulanger (1991), Faulstich (1995/1999/2006), Gaudin (1993/2014), Isquerdo e Oliveira (2001), Barros (2004), Krieger e Finatto (2004), uma vez que esses campos de investigação linguística nos possibilitam o entendimento e a sistematização das particularidades do léxico do CBMMA.

Metodologicamente, definimos como público-alvo desta investigação os profissionais das unidades especializadas de São Luís: o Batalhão de Bombeiros Marítimos (BBMAR) trabalha com resgate no mar; o Batalhão de Bombeiros de Emergência (BBEM) realiza

\footnotetext{
${ }^{1}$ Utilizaremos tanto a designação segmentos especializados quanto unidades especializadas, batalhões especializados e quartéis especializados para nos referirmos aos quartéis que possuem atividades específicas e diferenciadas dentro do CBMMA, além do quartel de combate a incêndio.

${ }^{2}$ Militares aposentados que já cumpriram no mínimo 30 anos de serviço efetivo.
} 
emergências médicas; o Batalhão de Busca e Salvamento (BBS) executa atividades de busca e salvamento; o Batalhão de Bombeiros Ambiental (BBA) combate incêndio florestal e urbano, além de fazer a captura e o resgate de animais; o $1^{\circ}$ Batalhão de Bombeiros Militar $\left(1^{\circ}\right.$ BBM) executa o serviço de Combate a Incêndio Urbano; a Seção de Combate a Incêndio em Aeródromo (SCI) combate somente incêndio e ocorrências em aeródromos, e a Academia de Bombeiros Militar "Josué Montello" (ABMJM) forma os oficiais da corporação.

São partícipes deste trabalho, profissionais que estão na ativa (não aposentados) nos batalhões especializados e aposentados (da reserva remunerada e/ou reformados) que já atuaram nas atividades operacionais desenvolvidas em São Luís/MA, assim, envolvemos profissionais atuantes no período que se estende de 1994 - primeiro ano logo após a emancipação do CBMMA em relação a PMMA - até 2019, ano de conclusão desta investigação.

Mais precisamente, trabalhamos com militares da ativa que tinham no mínimo 2 anos e no máximo 30 anos de efetivo serviço, de ambos os sexos: 11 homens e 11 mulheres, sendo que, entre os homens, 6 são reformados e cinco são da ativa; todas as onze mulheres estão na ativa ${ }^{3}$. Esses 22 sujeitos investigados foram divididos entre três faixas etárias: a faixa etária 1: de 18 a 25 anos; a faixa etária 2: de 30 a 55 anos e a faixa etária 3: de 60 anos em diante.

Para obtenção dos dados, em um primeiro momento, conversamos com militares reformados, os quais, por meio de narrativas orais livres, forneceram elementos norteadores para a elaboração do questionário usado nas entrevistas realizadas. Esse questionário é constituído de 41 questões organizadas em doze campos temáticos, são eles: formação, acessórios/equipamentos, alimentação, armamentos, atividades físicas/treinamentos, documentos oficiais, instalações, formas de tratamento, meios de comunicação, de transporte, produção de documentos e vestuário.

A importância do presente trabalho dá-se, ainda, pelo fato de existir, segundo as informações que tivemos até o momento de conclusão desta pesquisa, somente um documento denominado IN 004 “Terminologias de segurança contra incêndio”, do Corpo de Bombeiros Militar de Santa Catarina (CBMSC), criado em 2018. Dessa forma, nunca foi feita antes uma investigação mais abrangente sobre o léxico especializado do Corpo de Bombeiros no Brasil, ou seja, para além da atividade de combate a incêndio e, em especial, sobre o léxico especializado do CBMMA, o que corrobora a originalidade, pertinência e relevância deste trabalho.

\footnotetext{
${ }^{3}$ Critério adotado em razão de, até o momento, o CBMMA não possuir mulheres na reserva remunerada, ou seja, aposentadas.
} 
O presente trabalho tem sua relevância devido ao seu resultado poder servir de base para a realização de novas pesquisas sobre o léxico especializado do Corpo de Bombeiros em outros estados brasileiros para a potencialização da interação entre os membros de diferentes unidades do Corpo de Bombeiros no Brasil.

\section{Fundamentação teórica}

\section{Terminologia}

A Terminologia teve início na Europa e ganhou destaque em obras importantes, destacando-se o Dictionnaire des sciences, des lettres et des arts de Bouillet ${ }^{4}$, de 1864, que, segundo Barros (2004, p. 32), definia a Terminologia como a "[...] palavra que designa um conjunto de termos técnicos de uma ciência ou de uma arte e das ideias que elas representam".

O objeto de trabalho da Terminologia é o termo. Para Isquerdo e Oliveira (2001. p. 193), "as linguagens especializadas se caracterizam pelo emprego da terminologia, que representa a estrutura conceptual de determinadas matérias, enquanto os termos denominam os conceitos da rede estruturada da matéria em questão". Observa-se assim que os termos são os elementos que caracterizam a linguagem especializada, como exemplo encontrado em nosso trabalho cito o termo bradou, $V$, grito efetuado pelo bombeiro logo após o toque da sirene para atendimento de ocorrência. Enquanto que no dicionário Aurélio em sua primeira edição (1975) encontramos os seguintes verbetes: [Do lat. Blaterare] V.t.d. .1. Dizer em brados; exclamar gritar $A$ multidão bradava o nome do vencedor 2. Divulgar em alta voz; apregoar, pregoar: $O$ arauto bradon o edito real[...].

\section{Termo}

Sabemos que a terminologia possui como referência de estudo o termo, conforme Barros (2004, p.39), definido pelos órgãos internacionais de normalização como "designação, por meio de uma unidade linguística, de um conceito definido em uma língua de especialidade. Barros (2004, p.40) ainda nos esclarece que termo é uma unidade lexical com conteúdo especifico dentro de um domínio, sendo ainda chamado de unidade terminológica. Explica ainda que o conjunto de termos de uma área de especialidade chama-se conjunto terminológico ou terminologia.

Segundo Barros (2004, p.40), como signo linguístico das línguas de especialidade,

\footnotetext{
${ }^{4}$ Dicionário de ciências, letras e artes de Bouillet
} 
[...] o termo pode ser analisado em seus diferentes aspectos: do ponto de vista do significante e do significado, das relações de sentido que mantem com outros termos (sinônimos, homônimos, etc.), de seu valor sociolinguístico (usos, preferencias, conotações, processo de banalização etc.) e outros.

De acordo com Krieger e Finatto (2004, p.75), a Terminologia é um campo do conhecimento que possui identidade própria e estabelece o termo - um dos objetos de estudo da Terminologia - como um objeto distinto de ponderação e de tratamento. Ambos conceituam "termo" como sendo um elemento constitutivo da produção do saber, enquanto componente linguístico, cujas propriedades favorecem um único significado, ou seja, não admite a ambiguidade da comunicação especializada.

Segundo Krieger e Finatto (2004, p.77), um nome tem direito ao título de termo quando se distingue conceitualmente de outra unidade lexical de uma mesma terminologia. Um nome somente poderá adquirir um direito a denominação de termo quando este se diferenciar conceitualmente de uma outra unidade lexical dentro de uma mesma terminologia - uma das características do termo é o fato de a homonímia não se constituir um risco de ambiguidade.

\section{Socioterminologia}

A socioterminologia surge depois que Boulanger afirma, em 1991, em seu artigo "Une lecture sócio-culturelle de la terminologie" (Uma leitura sociocultural da terminologia), que o ponto de vista socioterminológico nasce como uma nova corrente, pois "vem atenuar os efeitos prescritivos exagerados de algumas proposições normativas" (BOULANGER, 1991, p.25).

Para Boulanger o termo Socioterminologia refere-se à disciplina que se ocupa da identificação e da categorização das variantes linguísticas dos termos em diferentes tipos de situações de uso da língua.

Pierre Auger (1993, p.53) já declarava conhecer a respeito da existência de "uma nova corrente chamada socioterminologia, em reação às escolas hipernormalizadoras desconectadas de situações linguísticas próprias a cada país”; essa corrente busca suas origens no cruzamento da sociologia da linguagem e da harmonização linguística.

\footnotetext{
5 Todas as traduções são de nossa responsabilidade. Em tradução livre: Uma leitura sociocultural da terminologia.
} 
Todavia, Gaudin em 1993, em sua tese de doutorado denominada - "Pour une socioterminologie - des problèmes sémantiques aux pratiques institutionnelles" ${ }^{\prime \prime}$ (Para uma socioterminologia problemas semânticos para práticas institucionais), discute com mais propriedade o estudo da terminologia voltado para o social, ao declarar que:

\begin{abstract}
"a socioterminologia, com o suposto de que deseja ultrapassar os limites de uma terminologia "de escrivão", deve localizar a gênese dos termos, sua recepção, sua aceitação, mas também as causas do insucesso e as do sucesso, no âmbito das práticas linguísticas e sociais concretas dos homens que empregam tais termos. Estas práticas são essencialmente aquelas que se exercem nas esferas de atividade. Eis porque a socioterminologia devia reencontrar as reflexões nos laços que se criam entre trabalho e linguagem" (GAUDIN 1993, p.216).
\end{abstract}

Para Faulstich (1999, p.167) a socioterminologia é, por sua vez um "campo da terminologia que se destina a depurar o conhecimento dos estudos especializados, científicos e técnicos, a auxiliar na planificação linguística e a oferecer recursos sobre as circunstâncias da elaboração desses discursos ao explorar as ligações entre a terminologia e a sociedade".

Ratifica ainda que é na teoria socioterminológica que se assenta os princípios e fundamentos que constituem os eixos principais de uma revisão prática e subsidiam as reformulações dos estudos anteriores. Assim, uma teoria socioterminológica realiza suas ações, numa mesma área de conhecimento, nos diferentes níveis de comunicação que dependem das circunstâncias de emissão, das características dos interlocutores, do suporte por meio do qual se dá a comunicação, entre outros.

Faulstich (1995, p.22-23) esclarece inclusive que, como prática do trabalho terminológico, fundamenta-se na análise das condições de circulação do termo no funcionamento da linguagem; como disciplina descritiva, estuda o termo sob a perspectiva linguística na interação social.

Nesse sentido, ela nos propõe que a pesquisa em Socioterminologia deve pautar-se nos princípios:

1) da sociolinguística, tais como os critérios de variação linguística dos termos no meio social e a perspectiva de mudança;

2) [e nos] da etnografia: as comunicações entre membros da sociedade capazes de gerar conceitos interacionais de um mesmo termo ou de gerar termos diferentes para um mesmo conceito. (FAULSTICH,1995, p. 22-23)

Por essa razão, que hoje os estudiosos da socioterminologia focam seu olhar aos diferentes discursos especializados, destaca-se aqueles ocorridos nos contextos orais, por entenderem que os termos em geral sofrem variações e por essa razão, suas variantes

\footnotetext{
${ }^{6}$ Em tradução livre: Para uma socioterminologia problemas semânticos para práticas institucionais
} 
precisam ser consideradas como fundamento da preparação de uma obra terminográfica.

Quanto ao critério de variação linguística, sabemos que o léxico pode sofrer diferentes variações de uso, as quais são condicionadas por variados fatores. Existem diferentes tipos de variações: geográfica ou diatópica, temporal ou diacrônica e aquela que se refere ao registro que é a variação diastrática.

Esta última se assemelha a nossa linha de trabalho dentro dos estudos da socioterminologia, por ela se manifestar tanto na língua comum quanto na língua de especialidade.

Desta maneira, dentro do princípio da etnografia, a interação ocorrida na sociedade por meio da comunicação de seus membros, permite um avanço e também uma heterogeneidade entre seus componentes a ponto de conceber novos termos e até mesmo diferentes termos para um mesmo conceito.

A exemplo em nossa dissertação no campo semântico alimentação, ao tratarmos sobre o termo torta, observamos que em grande parte das Unidades foi concebida a variação "bob esponja”, devido muitas das vezes a sua aparência, ao seu formato e a forma como os bombeiros a viam durante a alimentação, algo que se propagou dos mais antigos para os mais novos membros da Corporação.

No Brasil, os estudos em Socioterminologia tiveram início na universidade de Brasília - UNB, sob a coordenação da Professora Enilde Faulstich, por intermédio do grupo de pesquisa léxico e terminologia, tendo como objetivo organizar a socioterminologia em dois campos: o primeiro a socioterminologia, como prática do trabalho terminológico, fundamenta-se na análise das condições de circulação do termo no funcionamento da linguagem; e no segundo a socioterminologia, como disciplina descritiva, estuda o termo sob a perspectiva linguística na interação social.

Para Faulstich (2006, p. 29) essa corrente possibilitou criar o postulado máximo da socioterminologia, que é ter na base da pesquisa a variação linguística dos termos no meio social e, por consequência, entender a mudança terminológica como mecanismo resultante da pragmática discursiva.

Por essa razão, hoje, os estudiosos da Socioterminologia focam seu olhar nos diferentes discursos especializados, destacando-se aqueles ocorridos nos contextos orais, por entenderem que os termos de um modo geral variam e suas variantes, por sua vez, precisam ser consideradas na preparação de uma obra terminográfica.

Em síntese, de acordo com Faulstich (1995, p. 282), a Socioterminologia, como prática do trabalho terminológico, fundamenta-se na análise das condições de circulação do termo no funcionamento da linguagem. Nos apoiamos nessas palavras para demonstrar, 
por intermédio dos estudos dessa autora, que os estudos da Socioterminologia proporcionam conhecimentos acerca do funcionamento discursivo e social dos termos, rompendo com os estudos tradicionais da Terminologia, isto é, aprofundando o campo de ação de estudo dos termos.

Assim sendo, segundo Gaudin (2014, p.302), a língua que permite as interações da linguagem, por meio das quais a língua se recria e se renova. Não existe língua sem prática de linguagem; não existem práticas de linguagem sem língua.

Dessa forma, para Gaudin (2014, p. 444),

a circulação dos termos é projetada sob o ângulo da diversidade dos usos sociais, o que engloba o estudo das condições de circulação e da apropriação dos termos, considerados como signos linguísticos, e não como etiquetas de conceitos.

A partir dessa informação, compreendemos o sociotermo como o termo sob o ponto de vista social, sob o ponto de vista de sua circulação nas diferentes camadas sociais existentes dentro das mais diferentes especialidades e do convívio diário das pessoas no ambiente de trabalho.

O sociotermo é, portanto, o termo sob a perspectiva da diversidade de interações sociais, conforme Faulstich (1995, p.2), assim, reflete a diversidade social existente também dentro do ambiente laboral.

Sendo assim, concluímos que o sociotermo encontra-se dentro dos discursos especializados refletindo os usos sociais da língua.

\section{Metodologia}

A pesquisa foi desenvolvida no município de São Luís também pelo fato de somente na capital se ter os trabalhos executados especificamente pelas Unidades Operacionais Especializadas do Corpo de Bombeiros: a) o Batalhão de Bombeiros Marítimos (BBMAR), trabalha com resgate no mar; b) o Batalhão de Bombeiros de Emergência (BBEM), trabalha com emergências médicas; c) o Batalhão de Busca e Salvamento (BBS), executa atividades de busca e salvamento; d) o Batalhão de Bombeiros Ambiental (BBA), atua com incêndio florestal e urbano, além de captura e resgate de animais; e) o $1^{\circ}$ Batalhão de Bombeiros Militar ( $\left.1^{\circ} \mathrm{BBM}\right)$, executa o serviço de Combate a Incêndio Urbano; f) a Seção de Combate a Incêndio em Aeródromo (SCI), somente incêndio e ocorrências em aeródromos; g) a Academia de Bombeiros Militar "Josué Montello" (ABMJM), que operacionaliza a formação dos futuros Oficiais da Instituição. 
São sujeitos desta pesquisa os membros do CBMMA, tanto os efetivos da ativa (que estão exercendo suas funções) quanto os da reserva remunerada (aposentados). Considerando o espaço de tempo estabelecido como critério de escolha dos militares para esta pesquisa, definimos duas categorias: a primeira composta pelos aposentados, ou seja, pelos da reserva remunerada e a segunda, pelos bombeiros da ativa que tivessem ao menos 2 (dois) anos de efetivos serviço em uma das Unidades Especializadas investigadas e pelo menos em 1 (um) dos quartéis especializados da capital ou na Academia de Bombeiros Militar "Josué Montello" - ABMJM.

Os nossos informantes foram divididos e organizados em três faixa etárias: a faixa etária 1 - F1: de 18 a 29 anos; a faixa etária 2 - F2: de 30 a 55 anos e a faixa etária 3-F3: de 60 anos em diante.

Caracterizamos, então, os grupos de faixa etária da seguinte forma: faixa 1 - de 2 a 10 anos de serviço; da faixa 2 - de 15 a 30 anos de serviço; e na faixa 3, militar na reserva remunerada (aposentado).

Em uma primeira etapa, fizemos a coleta de dados in loco, por intermédio de uma entrevista informal com militares aposentados da Corporação, pois eles vivenciaram o período de dependência do CBMMA à Polícia Militar do Maranhão - PMMA e também o período de emancipação do CBMMA.

Posteriormente, e com base nesse primeiro momento, elaboramos um questionário constituído de 12 (doze) campos semânticos contendo 41 (quarenta e uma) perguntas fechadas, organizadas nos seguintes campos temáticos: formação, acessórios/equipamentos, alimentação, armamentos, atividades físicas/treinamentos, documentos oficiais, instalações, formas de tratamento, meios de comunicação, meios de transporte, produção de documentos e vestuário.

Resultados e Análises do Glossário do Corpo de Bombeiros Militar do Maranhão

Apresentamos uma pequena amostra do glossário de termos e sociotermos do CBMMA, obtidos durante o desenvolvimento da nossa pesquisa, por intermedio das entrevistas realizadas, junto aos colaboradores das unidades especializadas estudadas. E ainda nossas analises acerca desses resultados. 
Quadro - Termos e Sociotermos do CBMMA

\begin{tabular}{|c|c|c|c|c|c|}
\hline TERMO & SIGNIFICADO & $\begin{array}{l}\text { CAMPO SE- } \\
\text { MÂNTICO }\end{array}$ & $\begin{array}{c}\text { FAIXA } \\
\text { ETÁRIA }\end{array}$ & SEXO & UBM \\
\hline ACEIRO & Limpeza do terreno. & Formação & F1 e F2 & Ambos & $\mathrm{BBA}$ \\
\hline AGASALHA & Aceitar a situação. & Formação & F1 & Ambos & ABMJM \\
\hline ASPIRANTADO & $\begin{array}{c}\text { Estágio dos Aspiran- } \\
\text { tes. }\end{array}$ & $\begin{array}{l}\text { Unidade lexical en- } \\
\text { contrada }\end{array}$ & F1 & Ambos & ABMJM \\
\hline AZAR MILITAR & Falta de sorte. & Formação & F1 e F2 & Ambos & BBS/ABMJM \\
\hline BACANIZADO & Boa situação. & $\begin{array}{l}\text { Unidade lexical en- } \\
\text { contrada }\end{array}$ & $\mathrm{F} 1$ e F2 & Ambos & BBS \\
\hline BARRA & $\begin{array}{l}\text { Ano de entrada na } \\
\text { Corporação. }\end{array}$ & $\begin{array}{l}\text { Unidade lexical en- } \\
\text { contrada }\end{array}$ & Todas & Ambos & Todas \\
\hline BAIXADO & $\begin{array}{l}\text { Militar doente, de } \\
\text { atestado médico. }\end{array}$ & Formação & Todas & Ambos & Todas \\
\hline BIZONHO & $\begin{array}{l}\text { Militar que sempre } \\
\text { faz errado, que não } \\
\text { aprende. }\end{array}$ & Formação & Todas & Ambos & Todas \\
\hline BOB ESPONJA & Torta & $\begin{array}{c}\text { Unidade lexical en- } \\
\text { contrada }\end{array}$ & Todas & Ambos & Todas \\
\hline BRADOU & $\begin{array}{c}\text { Entrou uma ocorrên- } \\
\text { cia. }\end{array}$ & Formação & Todas & Ambos & Todas \\
\hline $\begin{array}{c}\text { BRANCA ÀS NU- } \\
\text { VENS }\end{array}$ & $\begin{array}{l}\text { Militar de folga do } \\
\text { serviço. }\end{array}$ & $\begin{array}{c}\text { Unidade lexical en- } \\
\text { contrada }\end{array}$ & $\mathrm{F} 1$ e $\mathrm{F} 2$ & Ambos & BBS \\
\hline BRAU BREU & $\begin{array}{l}\text { Lanche rápido ou re- } \\
\text { feição. }\end{array}$ & $\begin{array}{l}\text { Unidade lexical en- } \\
\text { contrada }\end{array}$ & $\mathrm{F} 1$ e $\mathrm{F} 2$ & Ambos & BBS \\
\hline CANGA & $\begin{array}{l}\text { Militar Parceiro nas } \\
\text { atividades. }\end{array}$ & Treinamento & Todas & Ambos & Todas \\
\hline CANÍCULA & Camisa de Botões. & $\begin{array}{c}\text { Unidade lexical en- } \\
\text { contrada }\end{array}$ & Todas & Ambos & Todas \\
\hline ETAPA & $\begin{array}{l}\text { Alimentação de quem } \\
\text { está de serviço. }\end{array}$ & Alimentação & F1 E F2 & Ambos & Todas \\
\hline GANDOLA & $\begin{array}{c}\text { Peça do Uniforme de } \\
\text { Prontidão. }\end{array}$ & Formação & Todas & Ambos & Todas \\
\hline $\begin{array}{c}\text { GUARDADORES } \\
\text { DA CIDADE }\end{array}$ & $\begin{array}{l}\text { Tomar de conta da ci- } \\
\text { dade. }\end{array}$ & $\begin{array}{c}\text { Unidade lexical en- } \\
\text { contrada }\end{array}$ & $\mathrm{F} 2$ & Masc. & $1^{\circ} \mathrm{BBM}$ \\
\hline GORRO & Boné & Formação & Todas & Ambos & Todas \\
\hline LENDIA & $\begin{array}{l}\text { Militar que não conse- } \\
\text { gue processar as in- } \\
\text { formações. }\end{array}$ & Formação & Todas & Ambos & Todas \\
\hline MACACO PRETO & Telefone fixo. & $\begin{array}{l}\text { Unidade lexical en- } \\
\text { contrada }\end{array}$ & F2 e F1 & Ambos & Todas \\
\hline MOITA & $\begin{array}{l}\text { Militar discreto, que } \\
\text { nunca aparece, se } \\
\text { mostra. }\end{array}$ & Formação & Todas & Ambos & Todas \\
\hline PHELPS & $\begin{array}{l}\text { Bombeiro que corre e } \\
\text { nada muito bem }\end{array}$ & $\begin{array}{l}\text { Unidade lexical en- } \\
\text { contrada }\end{array}$ & $\mathrm{F} 1$ & Ambos & ABMJM \\
\hline $\begin{array}{c}\text { PRESSÃO PRES- } \\
\text { SÃO }\end{array}$ & $\begin{array}{l}\text { Situação difícil pe- } \\
\text { rante o oficial. }\end{array}$ & $\begin{array}{c}\text { Unidade lexical en- } \\
\text { contrada }\end{array}$ & $\mathrm{F} 2$ & Masc. & $1^{\circ} \mathrm{BBM}$ \\
\hline SALA FRIA & $\begin{array}{l}\text { Denominação dada } \\
\text { pelas praças da SCI à } \\
\text { sala do comandante. }\end{array}$ & $\begin{array}{l}\text { Unidade lexical en- } \\
\text { contrada }\end{array}$ & F1 & Masc. & SCI \\
\hline SOBREAVISO & $\begin{array}{l}\text { Situação de pronti- } \\
\text { dão, aguardando para } \\
\text { ser acionado pela au- } \\
\text { toridade. }\end{array}$ & Formação & Todas & Ambos & Todas \\
\hline TINCHA & Comida, alimentação. & Alimentação & Todas & Ambos & Todas \\
\hline
\end{tabular}




\begin{tabular}{|c|c|c|c|c|c|}
\hline TINCHEIRO & $\begin{array}{c}\text { Militar que pede sem- } \\
\text { pre pede a comida } \\
\text { dos colegas. }\end{array}$ & Alimentação & Todas & Ambos & Todas \\
\hline TORAR & Ação de dormir. & $\begin{array}{c}\text { Unidade lexical en- } \\
\text { contrada }\end{array}$ & F1 & Ambos & ABMJM \\
\hline URSO-URSO & Ação urgente. & $\begin{array}{c}\text { Unidade lexical en- } \\
\text { contrada }\end{array}$ & F1 & Ambos & ABMJM \\
\hline
\end{tabular}

Fonte: Autor (2019)

Nossos dados foram coletados e analisados, a partir da aplicação do questionário constante de 42 questões elaboradas dentro de 12 campos semânticos.

Encontramos termos e/ou sociotermos específicos dos seguintes quartéis investigados:

(i) $-1^{\circ} \mathrm{BBM}-$ guardadores da cidade, pressão-pressão;

(ii) - BBA - GCIF, perneira, tapiri;

(iii) - BBMAR - rescue tub, QPM, M.A, USOA;

(iv) - BBEM - A02, A03, multicinto aranha;

(v) - ABMJM - olho de tandera, torar, phelps;

(vi) - SCI - sala fria, TWR, dez do k3;

(vii) - BBS - branca as nuvens, brau breu, bacanizado.

Como respostas apresentadas pelos 21 bombeiros participantes desta pesquisa, catalogamos 71 entradas divididas entre termos e sociotermos, registrados no glossário do CBMMA.

Dentre os campos semânticos investigados, aqueles que apresentaram um número mais significativo de termos e sociotermos, constantes nas atividades diárias e básicas dos entrevistados, foram: formação, acessórios/equipamentos, alimentação, documentos oficiais, vestuários e peculiaridades.

Os informantes apresentaram dificuldade em responder três questões, a primeira: Como se chama a peça do capacete que protege o militar quando de serviço operacional? A segunda: Qual era o nome do tipo de alimentação servido aos militares durante treinamento militar? E a terceira: Qual termo é/ era adotado para se referir a esposa do militar?

Comprovamos que os termos e/ou sociotermos mais frequentes encontrados em todos os quartéis foram: bradou, tincheiro, canga, moita, baixar, bisonho, etapa, tincha, bibico, boina, boletim, bradar, gorro, guarnição, melhorado, rancho e TFM.

Como quartel de destaque temos a $\mathrm{ABMJM}$, sendo a unidade que mais apresentou sociotermos, seguida da SCI e do BBEM.

Apenas um informante, pertencente a TS3 da SCI, não apresentou sociotermos 
durante a entrevista, pelo fato de não se lembrar naquele momento.

Quanto à variável tempo de serviço, os bombeiros com menos tempo de serviço foram aqueles que mais apresentaram termos e os sociotermos, tendo as mulheres lugar de destaque, pois foram as que mais apresentaram sociotermos, com ênfase as informantes lotadas na ABMJM, BBS, BBA e BBMAR, todas pertencentes a TS1.

Constatamos que a variável sexo não se mostrou relevante na nossa investigação, não havendo diferença acentuada entre a terminologia utilizada por homens e por mulheres dentro do CBMMA. Contudo, verificamos que na ABMJM, no BBMAR, BBS, BBEM e no BBA há uma predominância de uso por parte das mulheres quanto aos termos técnicos.

Quanto ao fornecimento de termos e sociotermos, sobressaíram às mulheres da $\mathrm{AB}$ MJM, futuras oficiais do CBMMA, esse resultado ocorreu em razão da grade curricular do curso, pois, durante os três anos no curso de formação, elas passam por todos os quartéis e ainda são preparadas para comandar, ensinar e promover a multiplicação dos conhecimentos.

Constatamos que a terminologia do CBMMA é de conhecimento e uso tanto de homens quanto de mulheres, o que confirma a participação das mulheres nos serviços especializados e desconstrói a ideia de que elas trabalhariam somente em setores administrativos dentro da Instituição.

Dentre os campos semânticos selecionados para compor o nosso questionário, o campo semântico formação mostrou-se bastante produtivo por gerar vários termos e, especialmente, sociotermos como lêndea, moita, baixar, bisonho, canga.

Ainda que a formação do bombeiro seja comum a todos, tanto a emancipação quanto a execução das atividades em campos específicos dentro do CBMMA geraram e ainda geram uma terminologia específica.

\section{Considerações finais}

Considerando os dados acima apresentados, o desenvolvimento da pesquisa com os membros das Unidades Especializadas do CBMMA, e a estruturação do questionário em 12 (doze) campos semânticos (formação, acessórios/equipamentos, alimentação, armamentos, atividades físicas/treinamentos, documentos oficiais, instalações, formas de tratamento para com o superior hierárquico, meios de comunicação, meios de transporte, produção de documentos e vestuário), observa-se, que:

a) existe uma vasta riqueza lexical neste universo dos sujeitos do CBMMA;

b) os homens assim como as mulheres conhecem e fazem uso dessas unidades lexicais; 
c) existem termos para as mais diversas situações, desde aquelas voltadas para os diferentes tipos de atendimentos efetuados pelos Bombeiros, cito: Bradou, termo adquirido por todos durante a formação em face da atividade fim da Corporação que é o de salvar vidas. Como também um termo específico designado para alimentação daqueles que estão de serviço: etapa;

d) nesse mesmo sentido de raciocínio, analisando o campo semântico alimentação, encontramos os termos: tincha, que diz respeito a comida, alimentação $e$ o tinxeiro, que significa pidão, aquele que fica a espreitar a comida alheia;

e) obtemos ainda, aquelas unidades lexicais específicas de determinado ambiente laboral, não ouvida e/ou encontrada em outro quartel, destaque para: guardadores da cidade, pressão-pressão, bacanizado e branca as nuvens. Todas, bastante significativas e importantes para o registro em glossário, objeto do nosso trabalho;

f) contata-se que é na formação, ou seja, quando da entrada, logo após aprovação em concurso público quer seja para soldado, ou para oficial, que durante o curso de formação, o militar passa adquirir parte desse léxico, conforme constatamos com os seguintes termos apresentados: agasalha, lendia, bizonho, moita, baixado e azar militar;

g) atestamos diante do quadro apresentado que a faixa etária 1 e 2 são aquelas que mais utilizam essas terminologias/socioterminologias.

Os resultados obtidos com a realização desta pesquisa ratificam a importância deste estudo para futuras pesquisas no âmbito das ciências do léxico e, mais especificamente, no âmbito dos estudos da terminologia das unidades dos Corpos de Bombeiros no Brasil.

Assim, diante do que apresentamos, demonstra quão importante e valioso torna-se nosso trabalho, uma vez que busca preencher um espaço existente quanto ao registro do patrimônio lexical do CBMMA, pois dessa forma, podemos proporcionar aos demais Corpos de Bombeiros, estudiosos da área, academias e também aos iniciantes na carreira um meio de estudo para contribuir com a sua formação.

\section{A SOCIOTERMINOLOGICAL STUDY OF THE LEXICON OF THE MILITARY FIRE DEPARTAMENT OF MARANHÃO.}

ABSTRACT: This article on the lexicon of the Military Fire Department of Maranhão (CBMMA), for registration and production of a glossary. It is justified by the emancipation in 1993, which allowed the origin of a specialized lexicon. It is based on terminology and socioterminology in the studies of Barros (2004), Faulstich (1995), Krieger and Finatto (2004). Methodologically, we used a questionnaire, the informants were distributed in three age ranges, as results, we identify terms like SpongeBob that refers to pie-type food. The present work is relevant for the study of the lexicon in the country.

KEYWORDS: Fire department; Glossary; Socioterminology; Terminology. 


\section{REFERÊNCIAS}

AUGER, Pierre. La commission de terminologie de l'Office de la langue française et la normalisation terminologique". In Terminogramme, 26-27, pp. 9-12, 1993.

BOULANGER, J. C. Une lecture socio - culturelle de la terminologie. Cahiers de linguistique sociale. (18). pp. 13-30. 1991.

FAULSTICH, Eneida. A função social da terminologia", Humanitas. São Paulo, FFLCH, USP, pp. 167183, 1999.

A socioterminologia na comunicação científica e técnica. Ciência Cultura. São Paulo, v.58, n.2, p.

27-31, June 2006. Available from. http:/ / cienciaecultura.bvs.br/scielo.php?script=sci rttext\&pid=S00096672500600200012 \&lng=em\&nrm=iso> acesso em 17 setembro 2019.

Socioterminologia: mais que um método de pesquisa, uma disciplina. Ciência da Informação, [S.l.], v. 24, n. 3, p. 1-14. dec. 1995. ISSN 1518-8353. Disponível em: <http://revista.ibict.br/ciinf/article/view/566/567>. Acesso em: 03 junho 2019.

FERREIRA, A. B. H. Aurélio. Novo dicionário da Lingua Portuguesa. 1ª. ed. Rio de Janeiro: Nova Fronteira, 1975.

GAUDIN, F. Socioterminologia: um itinerário bem-sucedido. As Ciências do Léxico: lexicologia, lexicografia, terminologia, 7: p. 293-309. 2014.

ISQUERDO, Negri Oliveira, OLIVEIRA, Ana Maria. P. P. de (Org.). As ciências do léxico: Lexicologia, Lexicografia, Terminologia. 2. ed. Campo Grande: Editora UFMS. 2001.

Livros:

BARROS, Lidia Almeida. Curso Básico de Terminologia. São Paulo: EDUSP, 2004.p.294

KRIEGER, M. da G.; FINATTO, M. J. B. Introdução à terminologia: teoria e prática. São Paulo: Contexto, 2004. $224 \mathrm{p}$.

Capítulos de livros:

SANTA CATARINA. Corpo de Bombeiros Militar. IN 004: terminologia de Segurança Contra Incêndio. Florianópolis, 2018.

Monografias, Teses e Dissertações:

GAUDIN, F. Socioterminologie. Des problèmes semantiques aux pratiques institutionnelles. Rouen, Université de Rouen, 1993.

Recebido em: 01/04/2021.

Aprovado em: 06/07/02021. 